\title{
Modulation of innate immune responses at birth by prenatal malaria exposure and association with malaria risk during the first year of life
}

Hamtandi Magloire Natama ${ }^{1,2,3}$, Gemma Moncunill ${ }^{4 \dagger}$, Eduard Rovira-Vallbona ${ }^{1 \dagger}$, Héctor Sanz ${ }^{4}$, Hermann Sorgho ${ }^{2}$, Ruth Aguilar ${ }^{4}$, Maminata Coulibaly-Traoré ${ }^{2}$, M. Athanase Somé2, Susana Scott ${ }^{5}$, Innocent Valéa ${ }^{2}$, Petra F. Mens ${ }^{6}$, Henk D. F. H. Schallig ${ }^{6}$, Luc Kestens ${ }^{1,3}$, Halidou Tinto ${ }^{2,7}$, Carlota Dobaño ${ }^{4 \dagger}$ and Anna Rosanas-Urgell ${ }^{1 * \dagger}$ (D)

\begin{abstract}
Background: Factors driving inter-individual differences in immune responses upon different types of prenatal malaria exposure (PME) and subsequent risk of malaria in infancy remain poorly understood. In this study, we examined the impact of four types of PME (i.e., maternal peripheral infection and placental acute, chronic, and past infections) on both spontaneous and toll-like receptors (TLRs)-mediated cytokine production in cord blood and how these innate immune responses modulate the risk of malaria during the first year of life.

Methods: We conducted a birth cohort study of 313 mother-child pairs nested within the COSMIC clinical trial (NCT01941264), which was assessing malaria preventive interventions during pregnancy in Burkina Faso. Malaria infections during pregnancy and infants' clinical malaria episodes detected during the first year of life were recorded. Supernatant concentrations of 30 cytokines, chemokines, and growth factors induced by stimulation of cord blood with agonists of TLRs $3,7 / 8$, and 9 were measured by quantitative suspension array technology. Crude concentrations and ratios of TLR-mediated cytokine responses relative to background control were analyzed.

Results: Spontaneous production of innate immune biomarkers was significantly reduced in cord blood of infants exposed to malaria, with variation among PME groups, as compared to those from the non-exposed control group. However, following TLR7/8 stimulation, which showed higher induction of cytokines/chemokines/growth factors than TLRs 3 and 9, cord blood cells of infants with evidence of past placental malaria were hyper-responsive in comparison to those of infants not-exposed. In addition, certain biomarkers, which levels were significantly modified depending on the PME category, were independent predictors of either malaria risk (GM-CSF TLR7/8 crude) or protection (IL-12 TLR7/ 8 ratio and IP-10 TLR3 crude, IL-1RA TLR7/8 ratio) during the first year of life.
\end{abstract}

Conclusions: These findings indicate that past placental malaria has a profound effect on fetal immune system and that the differential alterations of innate immune responses by PME categories might drive heterogeneity between individuals to clinical malaria susceptibility during the first year of life.

Keywords: Malaria in pregnancy, Prenatal malaria exposure, Innate immunity, Cytokines, Toll-like receptor, Malaria in infancy

\footnotetext{
* Correspondence: arosanas@itg.be

†Gemma Moncunill, Eduard Rovira-Vallbona, Carlota Dobaño and Anna

Rosanas-Urgell contributed equally to this work.

'Department of Biomedical Sciences, Institute of Tropical Medicine, B 2000

Antwerp, Belgium

Full list of author information is available at the end of the article
}

(c) The Author(s). 2018 Open Access This article is distributed under the terms of the Creative Commons Attribution 4.0 International License (http://creativecommons.org/licenses/by/4.0/), which permits unrestricted use, distribution, and reproduction in any medium, provided you give appropriate credit to the original author(s) and the source, provide a link to the Creative Commons license, and indicate if changes were made. The Creative Commons Public Domain Dedication waiver (http://creativecommons.org/publicdomain/zero/1.0/) applies to the data made available in this article, unless otherwise stated. 


\section{Background}

Despite the widespread implementation of Intermittent Preventive Treatment with sulfadoxine-pyrimethamine (IPTp-SP) to prevent malaria during pregnancy, infants in endemic countries are often born to mothers with placental malaria (PM). This is likely to increase their risk of a malaria infection in early childhood [1-7]. Factors explaining the association between PM and risk of malaria infection during infancy are still not well understood, but this association has been correlated with changes in malaria-specific fetal immunity [8]. Cord blood mononuclear cells of neonates born to mothers with PM can specifically respond to plasmodial asexual blood stage antigens, impacting on immune response to Plasmodium falciparum infection during infancy [9-15]. This prenatal exposure to malariainfected erythrocytes or their soluble products can lead to fetal immune priming to malaria blood stage antigens or to fetal immune tolerance in some infants [11, 16-20]. Nonetheless, factors that lead to this inter-individual difference in immune responses to malaria antigens upon prenatal exposure are unknown.

In early infancy, innate immunity is the main defense barrier of the host, as newborns have a naïve adaptive immune system [21, 22]. The immune cellular response starts with the recognition of pathogen molecules known as pathogen-associated-molecular patterns (PAMPs) by cells of the innate immune system through pattern recognition receptors (PRRs). Among these receptors, it has been shown that toll-like receptors (TLRs) are key initiators of innate immunity and promoters of adaptive immunity via direct and indirect mechanisms [23-25]. Ligands binding to TLRs generate intracellular signals, activate gene expression, and enhance the release of cytokines and chemokines $[26,27]$, which are important players in the pathogenesis of and protection against malaria [28]. Therefore, in early life, protection from infections relies extensively on innate immunity, and hence, factors that modulate the development of fetal innate immunity may drive variation in susceptibility to malaria between individuals in early infancy.

A few studies have reported that history of $P$. falciparum infections during pregnancy may have an effect on neonatal innate immune responses upon TLRs stimulation with implications for the outcome of newly encountered infections in early life [11, 29, 30]. Cytokine responses upon TLRs stimulation of cord blood cells have been found to be profoundly affected by either maternal peripheral infections occurring late in pregnancy [29, 30] or past PM [11]. In addition, it has been shown that exposure to malarial antigens in utero has different effects on the immune environment at birth, such as the number and/or activation status of immune cell populations, including antigen-presenting cells, regulatory, and effector $\mathrm{CD}^{+}{ }^{+} \mathrm{T}$ cells, depending on the type of exposure [10-15]. Overall, these data indicate that maternal peripheral and placental infections during pregnancy have an impact on cord blood cytokine responses to TLR agonists and that time and type of malaria exposure can skew cytokine responses towards a regulatory/tolerogenic or to a proinflammatory profile. In this regard, a tolerogenic profile would render infants more susceptible to malaria infections during the first year of life, whereas a proinflammatory profile can lead to more severe malaria episodes, whereas a Th1/Th17 profile could be protective.

Human TLRs that are known to be stimulated by malaria parasite-derived molecules include TLR2 (by glycosylphosphatidylinositol), TLR4 (by hemozoin), and TLR9 (by hemozoin and parasite DNA) [31-34]. However, the clinical relevance of TLR-mediated immune responses in the susceptibility to malaria has been mainly reported for endosomal PRRs such as TLR3, TLR7/8, and TLR9 in African children. Indeed, higher TLR3- and TLR7/8-mediated interleukin (IL)-10 responses at birth were found to be associated with a significant increased risk of $P$. falciparum infection in infants in Benin [30], whereas polymorphisms in TLR9 gene were associated with difference in susceptibility to malaria in Burundian and Ghanaian children [35, 36].

In this study, we assessed the effect of different types of prenatal malaria exposure (PME) on endosomal TLR-mediated cytokine responses in cord blood samples collected at birth, and we investigated the subsequent risk of malaria during the first year of life in a highly seasonal malaria endemic area of Burkina Faso.

\section{Methods}

\section{Study design and participants}

A prospective birth cohort study was nested within the COSMIC trial (NCT01941264). In brief, COSMIC was a cluster randomized controlled trial investigating the protective efficacy of adding community-scheduled screening and treatment of malaria during pregnancy (CSST) to the standard IPTp-SP (CSST/IPTp-SP; intervention arm) compared to IPTp-SP alone (control arm) in Burkina Faso, Benin, and The Gambia [37]. The CSST extension strategy was implemented through monthly screening using rapid diagnostic tests (RDTs) and treatment of malaria infections with artemether-lumefantrine (AL). Pregnant women in both arms who experienced clinical malaria during pregnancy were also treated with AL. In addition, all pregnant women in the two arms were further screened for malaria during antenatal care (ANC) booking using light microscopy (LM). Furthermore, additional blood spots on filter papers during community screening (CSST/IPTp-SP arm) and at each ANC visit (both CSST/IPTp-SP and IPTp-SP arms) were collected for posterior malaria diagnostic by quantitative real-time polymerase chain reaction (qPCR). At the time of delivery, placenta biopsies and cord blood samples in heparin containing tubes were collected from mother-child pairs. Placenta histology was performed later 
on within the parent COSMIC trial, while cord blood samples were immediately processed. Of the 734 mother-child pairs enrolled in the birth cohort in Burkina Faso, a subgroup of 313 mothers and their offspring were included for the present study. Those mother-child pairs were selected based on the history of malaria infection during pregnancy (using LM and RDT results) and the availability of cord blood samples for immunological assays at delivery (Fig. 1). The study was conducted in the rural health district of Nanoro, a high and seasonal malaria transmission area in Centre-West of Burkina Faso [38].

\section{Recruitment and follow-up}

The recruitment procedure of the mother-child pairs and details of the 1-year follow-up of infants included in the birth cohort study have been previously described $[39,40]$. Shortly, pregnant women from Nanoro participating in the COSMIC trial were asked at antenatal care visits to participate in the birth cohort study prior to delivery. At delivery, healthy newborns with their mothers were enrolled after informed consent was obtained. Exclusion criteria were presence of major congenital malformation, chronic disease, or signs of cerebral asphyxia. Clinical malaria episodes in infants were monitored by passive case detection, for which mothers were encouraged to seek care in peripheral health centers at any time their child felt sick. At each attendance to health facilities, a clinical examination was performed and mothers were asked for previous health events. In the case of fever (axillary temperature $\geq 37.5^{\circ} \mathrm{C}$ ) or history of fever in the previous $24 \mathrm{~h}$, a malaria RDT was performed and positive infants were treated according to national guidelines.

\section{Sample collection}

Sample collection procedures have been described elsewhere [41]. In brief, at time of delivery, approximately $200 \mu \mathrm{L}$ of maternal peripheral blood was obtained by finger-prick for blood smear preparation and blood spot on filter paper. A placental tissue section was collected from the maternal side and preserved in 10\% neutral buffer formalin at $4{ }^{\circ} \mathrm{C}$ for histology examination. In addition, cord blood (approximately $10 \mathrm{~mL}$ ) was collected in heparin-containing tubes by venipuncture of the umbilical vein for TLRs stimulation assays. The remaining cord blood in the heparinized tube was transferred from the peripheral health centers to the laboratory at the Clinical Research Unit of Nanoro (CRUN) for processing within 4 h. Peripheral blood was collected post-partum by finger-prick from each infant visiting the health facilities with presence of fever or history of fever in the previous $24 \mathrm{~h}$, and used for RDT, blood smear, and spots on filter paper (Whatman 3MM).

\section{Toll-like receptors stimulation assay}

TLRs stimulations of cord blood mononuclear cells were performed using fresh whole cord blood samples. Briefly, cord blood samples were diluted 1:1 with RPMI 1640 (1X, Gibco) and five aliquots of $200 \mu \mathrm{l}$ were prepared. One aliquot was left unstimulated and the other four were stimulated either with the synthetic analog of

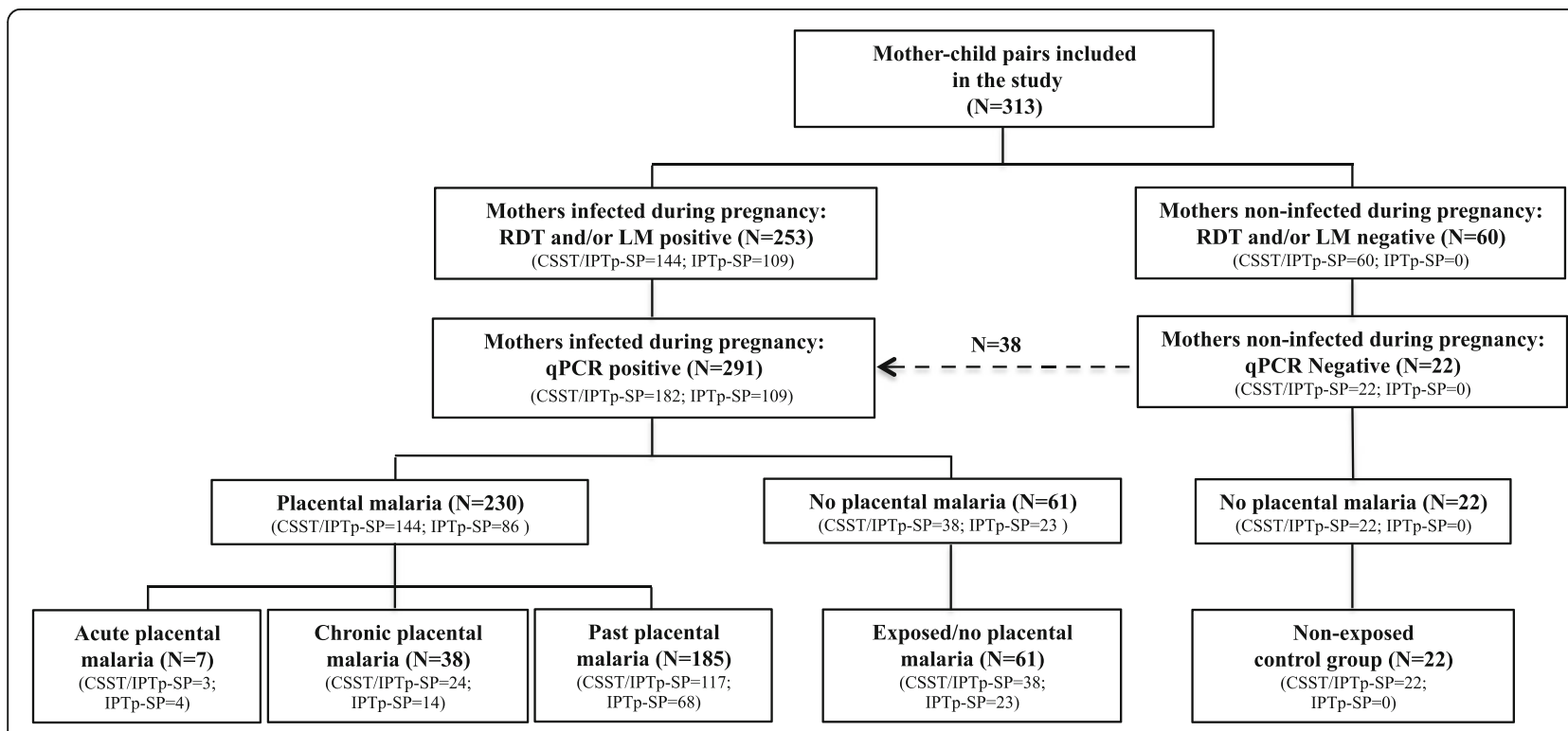

Fig. 1 Categories of prenatal malaria exposure (PME). Pregnant women infected during pregnancy with placental malaria (PM; acute, chronic, or past) or without PM (exposed/no PM) were recruited from both COSMIC study arms [37]. Pregnant women included in the non-exposed control group were only recruited among the CSST/IPTp-SP intervention arm: all of them had negative RDT/LM results for malaria infection in monthly screenings and at antenatal care visits that were later on confirmed by $\mathrm{QPCR}$ and, with no evidence of placental malaria 
dsRNA-PolyI:C (TLR3 ligand; $10 \mu \mathrm{g} / \mathrm{mL}$; InvivoGen, San Diego, USA), imidazoquinoline (R848, TLR7/8 ligand; $10 \mu \mathrm{g} / \mathrm{mL}$; InvivoGen, San Diego, USA), the synthetic type B unmethylated CpG dinucleotide (ODN2006-1, TLR9 ligand, $5 \mu \mathrm{M}$; InvivoGen, San Diego, USA) or with a mixture of phorbol myristate acetate (PMA), and ionomycin as positive control (PMA $0.1 \mu \mathrm{g} / \mathrm{mL}$ and ionomycin $1 \mu \mathrm{g}$ / $\mathrm{mL}$; Sigma-Aldrich, Schnelldorf, Germany). After $24 \mathrm{~h}$ of incubation at $37{ }^{\circ} \mathrm{C}$ in $5 \% \mathrm{CO}_{2}$, supernatants were collected following a centrifugation at $500 \mathrm{~g}$ for $5 \mathrm{~min}$, then frozen at $-80{ }^{\circ} \mathrm{C}$. Culture supernatants were subsequently shipped frozen to ISGlobal (Barcelona) for cytokines, chemokines, and growth factors measurement.

Cytokines, chemokines, and growth factors quantification Supernatants were thawed at room temperature, centrifuged at $1000 \mathrm{~g}$ for $10 \mathrm{~min}$ and then diluted in a ratio of 1:5 in RPMI 1640 (1X, Gibco). Cytokines, chemokines, and growth factors levels were determined using a fluorescent bead-based multiplex immunoassay (Human Cytokine Magnetic 30-Plex Panel kits, Novex ${ }^{\oplus}$, Life Technologies $^{\mathrm{Ts}}$, USA). Twenty-five microliters of each supernatant were tested in single replicates applying a modification of the manufacturer's protocol, which implies using half the volume of each reagent except for the washing buffer. The 30-Plex panel kit includes the following: interleukin (IL)-2, IL-4, IL-5, IL-6, IL-7, IL-8, IL-10, IL-13, IL-15, IL-17, IL-1 $\beta$, IL-1RA, IL-2R, IL-12(p40/p70), tumor necrosis factor (TNF), interferon (IFN)- $\gamma$, IFN- $\alpha$, IFN- $\gamma$ inducible protein 10 (IP-10), monocyte chemottractant protein (MCP)-1, macrophage inflammatory protein (MIP)-1 $\alpha$, MIP-1 $\beta$, eotaxin, RANTES, monokine-induced by IFN- $\gamma$ (MIG), vascular endothelial growth factor (VEGF), hepatocyte growth factor (HGF), epidermal growth factor (EGF), fibroblast growth factor (FGF) basic, granulocyte-colony stimulating factor (G-CSF), and granulocyte-macrophage colony stimulating factor (GM-CSF). Samples were acquired on a Luminex ${ }^{\oplus} 100 / 200^{\text {TM }}$ instrument using Xponent 3.1 software. Median fluorescent intensity (MFI) data was analyzed using the drLumi 0.1.2 $\mathrm{R}$ package [42], in which concentration of each analyte was determined by interpolating the MFI to a standard curve (plotted using a 5- or 4-parameter logistic function) of twofold 16 serial dilutions prepared from a reference sample provided by the manufacturer. The limits of quantification (lower, LLOQ and upper, ULOQ) for each analyte and plate were obtained applying the $20 \%$ coefficient of variation method [43-45] in drLumi. Any analyte with a value below the LLOQ was given a value of half the LLOQ for that analyte, and any analyte with a value above the ULOQ was given a value of two times the ULOQ of that analyte.

\section{Malaria detection and definitions}

SD-Bioline malaria antigen P.f test (05FK50, Standard Diagnostics, Inc., Korea) detecting PfHRP2 was used for malaria RDT according to the manufacturer's instructions. The microscopic examination of thick blood smears stained with Giemsa (10\%) was performed according to standard procedures [46]. Dried blood spots on filter paper were used for DNA extraction (QIAamp 96 DNA blood kit, Qiagen, Germany) and, P. falciparum detection of $P f$-varATS by qPCR, as previously described [41]. Data on past history of malaria infections during pregnancy and histological examination of placental tissues were obtained from the COSMIC trial [37]. A clinical malaria episode was defined as the detection of $P$. falciparum parasites by qPCR and presence of fever. PM infections were defined by histological examination as follows: (i) acute infection (parasites present, malaria pigment absent), (ii) chronic infection (parasites and malaria pigment present), (iii) past infection (parasites absent but pigment present), and (iv) no infection (both parasites and malaria pigment absent). PME was categorized based on placental infection (past, chronic, acute) and maternal peripheral infection as shown in Fig. 1. The non-exposed control group was composed of pregnant women only recruited among the CSST/IPTp-SP intervention arm who had negative RDT/ $\mathrm{LM}$ and $\mathrm{qPCR}$ results at each screening and ANC visit and negative placental histology.

\section{Statistical analysis}

Statistical analysis was performed using $\mathrm{R}$ statistical package version 3.2.3 [47]. Cytokine concentrations (both crude and ratios between stimulated and unstimulated samples) were $\log _{10}$-transformed after assessing the distribution of each cytokine using normality plots for each cytokine across TLR stimulations. To explore sample clusters by TLR stimulation, data were plotted by using principal component analysis (PCA) and the first two components were used to show associations.

To assess the effect of PME on TLR-mediated cytokine responses, ANOVA test was used to compare the mean of cytokine responses between groups of PME for significant variance among the mean of cytokine responses. Benjamini-Hochberg method was applied to adjust $p$ values for multiple comparisons [48]. Maternal- and infant-related co-variables including gravidity, low birth weight (LBW), birth season, newborn sex, and ethnicity were used to adjust the effect of PME on cytokine responses in linear regression models.

The association between TLR-mediated cytokine responses at birth and the risk of clinical malaria during the first year of life was assessed in univariable and multivariable Cox proportional-hazard models. Proportionality of hazards assumption and functional form of each variable adjusted in the Cox models was examined using 
Schoenfeld residuals analysis and p-splines, respectively. Secondary variables that showed significant association with malaria during the first 12 months of life were determined in Kaplan-Meier survival analyses (log-rank test $P$ value $<0.05)$ and included in the Cox proportional-hazard regression models. A $P$ value $<0.05$ was considered statistically significant.

\section{Results}

\section{Characteristics of study participants}

The characteristics of the participants included in this study are presented in Table 1 . The mean age of pregnant women at enrollment was 26.1 years, and the majority of them were multigravida (63\%). More than two thirds of deliveries (77.6\%) occurred during the malaria high-transmission season (July-December). The mean birth weight of the newborns was $3009 \mathrm{~g}$, while $9.6 \%$ had a low birth weight (LBW). In total, 291 newborns (93\%) were exposed to malaria parasites and/or antigens in utero. The majority of the newborns were born to mothers with past PM $(59.1 \%$ [185/313]) followed by those born to mothers who had either clinical malaria $(N=6)$ or asymptomatic infection $(N=55)$ during pregnancy but with no evidence of PM at delivery (19.5\% [61/313]). Few infants were born to mothers with acute PM at delivery (2.2\% [7/313]). There was a higher but non-significant proportion of females than males among the newborns $(P=0.158)$.

\section{TLR-mediated cytokine responses}

Overall variance of cytokine responses between subjects and stimuli is shown in Fig. 2 by PCA. PC1 and PC2 contribute to explain $59.2 \%$ and $5.2 \%$ of the variance, respectively. Overall, the responses to TLR3 and TLR9 clustered together with the unstimulated samples in contrast to distinct clustering of TLR7/8 responses, suggesting that TLR3 and TLR9 ligands did not induce-or induced low responses-for most of the analytes. This pattern is further illustrated by $\log _{10}$ of ratios of stimulated and unstimulated samples for each TLR agonist (Additional file 1: Figure S1 and S2), which show that few cytokines were produced above the background level following stimulations of TLR3 or TLR9. Compared to unstimulated samples, IP10 was the only analyte significantly induced by the TLR3 agonist (ANOVA, $P<$ 0.001 ), while those significantly induced in response to TLR9 included IFN- $\alpha$, IL-1RA, MCP-1, and IP-10 (ANOVA, $P \leq 0.006$ ). For TLR7/8 stimulation, all analyzed cytokines (with the exception of eotaxin, $P=0.319$ ) had a significantly higher concentration than that of unstimulated samples (ANOVA, $P<0.05$ ).

\section{PME and cytokine responses at birth}

Variation in cytokine production by PME category is shown as boxplots in Additional file 2: Figure S3-S6.
Results indicate that PME modifies innate immune responses to TLR stimulations at different magnitudes, depending on the PME category. The main effect was observed in responses to TLR7/8 stimulation (Additional file 2: Figure S5), being past PM more frequently associated with a significantly higher production of cytokine levels (i.e., IFN- $\alpha$, IL-2, MIP-1 $\alpha$, RANTES, FGF, G-CSF, GM-CSF) compared with the non-exposed control group (ANOVA, $P<0.05$ ). As expected, there was little variation in cytokine levels according to PME category following stimulations by TLR3 or TLR9, as these PRRs ligands induced very low cytokine production. The concentrations of cytokines in unstimulated samples also differed between PME categories. Overall, there was a tendency of lower cytokine levels among infants prenatally exposed to malaria (any category) than in non-exposed infants (Additional file 2: Figure S3). The significant variations were mostly observed with past PM on IL-1ß, TNF, IL-7, IL-15, IL-2, IL-4, G-CSF, GM-CSF, HGF, and VEGF and with chronic PM on IL-7, IL-15, IL-2, IFN- $\gamma$, IL-17, and GM-CSF (ANOVA, $P<$ 0.05). The comparison of biomarker levels in unstimulated samples from the exposed infants did not show a significant difference between PME groups. However, the trend analysis revealed a significant trend towards decreasing production among unstimulated samples from infants born to mothers with peripheral infection to those born to mothers with PM (past, chronic, and acute, respectively) for some biomarkers including IL-10 ( $P$ for trend $=0.024)$, IL-12 $(P$ for trend $=0.042)$, and GM-CSF ( $P$ for trend $=0.032$ ).

Innate immune response to TLR stimulation by PME was further investigated using multivariable linear regression models. The co-factors, besides PME, affecting cytokine responses in each stimulation assessment used in subsequent models are listed in Additional file 3: Table S1. The confounding factors, including gravidity, ethnicity, birth season, LBW, and newborn sex, were controlled for in subsequent models. Results confirmed that following stimulation with TLR7/8 agonist, infants born to mothers with past PM produced a significantly larger breadth of analytes compared to non-exposed individuals (17 cytokines related to all the functional classes analyzed, except anti-inflammatory and Th17-related cytokines) (Table 2). Significant differences were also observed in infants born to mothers with chronic PM (i.e., MIP-1 $\alpha$, MIP-1 $\beta$, FGF, G-CSF, and GM-CSF $)(P<0.05$, Table 2). In the case of infants born to mothers with acute PM, only two growth factors (FGF and GM-CSF) had significantly higher mean ratios compared to non-exposed infants, whereas only GM-CSF was higher in infants born to mothers infected during pregnancy but with no PM at delivery. Stimulation of TLR3 resulted in higher IP-10 responses among infants born 
Table 1 Characteristics of study participants

\begin{tabular}{|c|c|c|c|c|c|c|c|}
\hline Characteristics & $\begin{array}{l}\text { Overall cohort } \\
(N=313)\end{array}$ & $\begin{array}{l}\text { Non-exposed } \\
(N=22)\end{array}$ & $\begin{array}{l}\text { Exposed no PM } \\
(N=61)\end{array}$ & $\begin{array}{l}\text { Past PM }(N= \\
185)\end{array}$ & $\begin{array}{l}\text { Chronic PM } \\
(N=38)\end{array}$ & $\begin{array}{l}\text { Acute PM } \\
(N=7)\end{array}$ & $P$ value \\
\hline \multicolumn{8}{|l|}{ Maternal characteristics } \\
\hline Age (years, mean $\pm S D$ ) & $26.1 \pm 6.2$ & $28.4 \pm 6.4$ & $27.7 \pm 6.0$ & $25.5 \pm 6.0$ & $23.8 \pm 5.7$ & $28.3 \pm 7.2$ & $<0.001$ \\
\hline Gravidity (N (\%)) & & & & & & & $<0.001$ \\
\hline Primigravida & $58(18.5)$ & $1(4.5)$ & $2(3.3)$ & $40(21.6)$ & $15(39.5)$ & $0(0.0)$ & \\
\hline Secundigravida & $58(18.5)$ & $2(9.1)$ & $10(16.4)$ & $38(20.5)$ & $7(18.4)$ & $1(14.3)$ & \\
\hline Multigravida & $197(63.0)$ & 19 (86.4) & $49(80.3)$ & $107(57.9)$ & $16(42.1)$ & $6(85.7)$ & \\
\hline ITN use (N (\%)) & $219(70.0)$ & $19(86.4)$ & $47(77.0)$ & $128(69.2)$ & $21(55.3)$ & $4(57.1)$ & 0.061 \\
\hline $\begin{array}{l}\text { MiP preventive strategy in COSMIC } \\
\text { trial }(\mathrm{N}(\%))\end{array}$ & & & & & & & $<0.001$ \\
\hline Standard IPTp-SP & $109(34.2)$ & - & $23(37.7)$ & $68(36.8)$ & $14(36.8)$ & $4(57.1)$ & \\
\hline CSST/IPTp-SP & $204(65.2)$ & $22(100.0)$ & $38(62.3)$ & $117(63.2)$ & $24(63.2)$ & $3(42.9)$ & \\
\hline $\begin{array}{l}\text { SP doses uptake (women who received } \\
\geq 2 \text { doses, } N(\%) \text { ) }\end{array}$ & $293(93.6)$ & $21(95.5)$ & $55(90.2)$ & $178(96.2)$ & $32(84.2)$ & $7(100.0)$ & 0.055 \\
\hline $\begin{array}{l}\text { AL treatment (women treated at least } \\
\text { once, } N(\%) \text { ) }\end{array}$ & $67(21.4)$ & - & $7(11.5)$ & $43(23.2)$ & $14(36.8)$ & $3(42.8)$ & 0.002 \\
\hline $\begin{array}{l}\text { Gestational age at enrollment (median } \\
\text { (IQR), weeks) }\end{array}$ & $20(19-22)$ & $20(18-26.5)$ & $20(20.5-25.5)$ & $20(19-21)$ & $20(16-21)$ & $20(20-25)$ & 0.445 \\
\hline \multicolumn{8}{|l|}{ Infants characteristics } \\
\hline Sex (females, $N(\%)$ ) & $169(54.0)$ & $7(31.8)$ & $36(59.0)$ & $105(56.8)$ & $19(50.0)$ & $2(28.6)$ & 0.110 \\
\hline $\begin{array}{l}\text { Birth season (malaria high-transmission } \\
\text { season, } N(\%) \text { ) }\end{array}$ & $243(77.6)$ & $14(63.6)$ & $44(72.1)$ & $141(76.2)$ & $37(97.4)$ & $7(100.0)$ & 0.002 \\
\hline Birth weight $(g$, mean $\pm S D)$ & $3009 \pm 429.6$ & $3119.1 \pm 441.7$ & $3041.5 \pm 360.5$ & $2988.2 \pm 439.1$ & $\begin{array}{l}2967.1 \pm \\
499.8\end{array}$ & $3169.3 \pm 228.4$ & 0.470 \\
\hline LBW (<2500 g) (no. (\%)) & $30(9.6)$ & $1(4.5)$ & $3(4.9)$ & $20(10.8)$ & $6(15.8)$ & $0(0.0)$ & 0.371 \\
\hline Ethnicity (N (\%) & & & & & & & 0.017 \\
\hline Mossi & $276(88.2)$ & $21(95.4)$ & $55(90.1)$ & $164(88.6)$ & $31(81.6)$ & $5(71.4)$ & \\
\hline Gourounsi & $34(10.8)$ & $1(4.6)$ & $4(6.6)$ & $21(11.4)$ & $7(18.4)$ & $2(28.6)$ & \\
\hline Fulani & $3(1.0)$ & $0(0.0)$ & $2(3.3)$ & $0(0.0)$ & $0(0.0)$ & $0(0.0)$ & \\
\hline $\begin{array}{l}\text { Follow-up time (total time at risk, } \\
\text { person-months) }\end{array}$ & 2782.6 & 175.1 & 544.7 & 1664.1 & 330.4 & 68.3 & \\
\hline Clinical malaria episode (N (\%)) & $189(60.4)$ & $11(50.0)$ & $37(60.7)$ & $113(61.1)$ & $24(63.2)$ & $4(57.1)$ & 0.872 \\
\hline $\begin{array}{l}\text { Time to first clinical malaria episode } \\
\text { (median, months) }\end{array}$ & 10.3 & 10.2 & 10.6 & 10.2 & 10.5 & 11.4 & 0.990 \\
\hline
\end{tabular}

PM placental malaria, SD standard deviation, $L B W$ low birth weight, ITN insecticide-treated net, IQR interquartile range, MiP malaria in pregnancy, COSMIC community-based scheduled screening and treatment of malaria in pregnancy: a cluster randomized trial, IPTp-SP intermittent preventive treatment during pregnancy with Sulfadoxine-pyrimethamine, CSST/IPTp-SP community-based scheduled screening and treatment of malaria in combination with the standard IPTp$\mathrm{SP}, A L$ artemether-lumefantrine

to mothers with past and chronic PM $(P=0.026$ and $P=$ 0.008 , respectively), but lower $\mathrm{IL}-5$ responses $(P=0.046$ and $P=0.033$, respectively). Finally, TLR9-mediated FGF and G-CSF responses were found to be significantly higher in infants born to mothers with past PM compared to the control group $(P=0.028$ and $P=0.016$, respectively), whereas IL-5 responses were significantly lower in infants born to mothers with chronic PM compared with those in the non-exposed control group $(P=0.009)$.

Results from the multivariable models confirmed decreased levels of cytokines in unstimulated samples from infants prenatally exposed to malaria compared to the non-exposed control group: lower cytokine responses were found in past PM exposed group (20 cytokines from all the functional classes analyzed), chronic PM (10 cytokines from all the functional classes, except proinflammatory cytokines), acute PM (IL-7 only), and for peripheral infections during pregnancy (IL-7, IL-15, IL-13, IL-17, HGF, VEGF).

\section{TLR-mediated cytokine responses and risk of clinical malaria during the first year of life}

Data on malaria incidence and prevalence among the overall birth cohort has been described elsewhere [39]. 


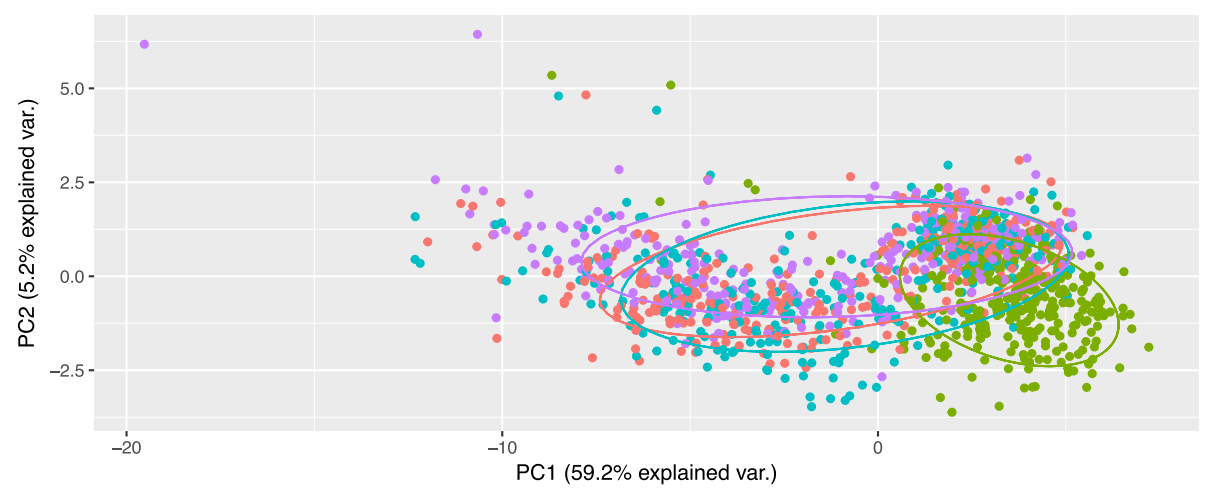

Fig. 2 Principal component analysis of cytokine responses to TLR agonists. PCA showing the variance in cytokine responses to the three TLR agonists and unstimulated samples. Ellipses represent the clusters estimated based on principal components 1 and 2

In the subgroup of infants included in the present analysis, malaria incidence was $60.4 \%(189 / 313)$ with a median survival time of 10.3 months (Table 1). Among the potential confounding factors analyzed (i.e., gravidity, PME, LBW, birth season, newborn sex, ethnicity, insecticide-treated net (ITN) usage by mothers), PME (Fig. 3) and LBW (Fig. 4) were found to be significantly associated with the risk of clinical malaria and, thus, were included in the Cox multivariable regression analyses. In particular, we found that infants born to mothers with PM had a significantly lower risk of clinical malaria during the first 6 months of life, while they were at higher risk of clinical malaria from age 6 to 12 months, compared to infants born to mothers with no PM. In addition, infants born with LBW had a significant shorter time to first clinical malaria episode than those born with a normal birth weight. Although birth season was not significantly associated with the risk of clinical malaria (Fig. 5), it was included in the models using an interaction term with the timing of clinical malaria to account for differences in the risk of infection between infants due to the high seasonality in malaria transmission in Burkina Faso.

Using crude concentration of cytokines, we found that higher concentrations of eotaxin (in both unstimulated and TLR7/8-stimulated samples), IL-7 (in TLR3-stimulated samples), GM-CSF (in TLR7/8-stimulated samples), and IL-1 $\beta$ (in TLR9-stimulated samples) in the cord blood at birth were significantly associated with an increased risk of subsequent clinical malaria episodes during the first year of life (Table 3). In contrast, an increase in the concentration of IP-10 in TLR3 and TLR9 stimulations was associated with a decreased risk of clinical malaria occurrence in early infancy. When considering biomarkers ratios, increases in TLR3-mediated IL7 response were predictive of an increased risk of clinical malaria attack, while higher TLR9-mediated eotaxin responses and TLR7/8-mediated
IL-1RA and IL-12 responses had a protective effect against developing a malaria episode during the first year of life (Table 3). Remarkably, TLR-mediated responses of some biomarkers, which showed a significant prediction of malaria protection/risk during the first 12 months of life (i.e., IL-12 TLR7/8 ratios, IL-1RA TLR7/8 ratios, GM-CSF TLR7/8 crude, IP-10 TLR3 crude), were significantly influenced by in utero exposure to malaria parasites (Additional files 2 and 3) indicating the clinical relevance of the modulation of newborn's innate immune responses by PME.

\section{Discussion}

In this study, we investigated the impact of different manifestations of malaria in pregnancy on both spontaneous and TLR-mediated cytokine production by cord blood cells at birth and we assessed whether these cytokines predicted malaria risk/protection in infancy. Overall, we found that PME has a profound effect on the fetal immune system and that the differential modulation of infants' innate immune responses by PME could have important implications with regards to malaria susceptibility in infancy. Indeed, we observed that spontaneous cytokine, chemokine, and growth factor production were all significantly lower in samples from exposed versus non-exposed infants. However, following TLR7/8 stimulation, cord blood cells from mothers with past PM (pigment only) were hyper-responsive in comparison to those without evidence of prenatal exposure. Importantly, we identified some responses (both spontaneous and following TLR stimulation) associated with differential malaria risk in infancy.

To our knowledge, this study reports for the first time the effect of these categories of PME on TLR-mediated innate immune responses, as previous studies have focused on the overall effect of PM and/or other types of PME on PRR-mediated cytokines responses $[9,29,30$, 49]. It has been shown that malaria pigment in the 
Table 2 Multivariable linear regression analyses assessing the effect of prenatal malaria exposure (PME) categories on TLR-mediated cytokine responses at birth

\begin{tabular}{|c|c|c|c|c|c|c|c|c|c|}
\hline \multirow{2}{*}{\multicolumn{2}{|c|}{ Cytokines* $^{*}$}} & \multicolumn{2}{|c|}{ Exposed/no PM vs non-exposed } & \multicolumn{2}{|c|}{ Past PM vs non-exposed } & \multicolumn{2}{|c|}{ Chronic PM vs non-exposed } & \multicolumn{2}{|c|}{ Acute PM vs non-exposec } \\
\hline & & Coeff (SE) & $P$ & Coeff (SE) & $P$ & Coeff (SE) & $P$ & Coeff (SE) & $P$ \\
\hline \multicolumn{10}{|c|}{ TLR7/8 responses using $\log _{10}$ of ratio cytokines concentrations } \\
\hline \multirow[t]{4}{*}{ Pro } & IFN-a & $0.15(0.08)$ & 0.079 & $0.19(0.08)$ & 0.018 & $0.09(0.09)$ & 0.359 & $0.08(0.15)$ & 0.591 \\
\hline & IL-1RA & $0.15(0.12)$ & 0.223 & $0.22(0.11)$ & 0.049 & $0.15(0.14)$ & 0.263 & $0.22(0.22)$ & 0.308 \\
\hline & $\| \mathrm{L}-1 \beta$ & $0.13(0.20)$ & 0.522 & $0.36(0.18)$ & 0.049 & $0.32(0.22)$ & 0.140 & $0.11(0.35)$ & 0.765 \\
\hline & TNF & $0.28(0.24)$ & 0.238 & $0.55(0.22)$ & 0.013 & $0.31(0.26)$ & 0.229 & $0.36(0.42)$ & 0.387 \\
\hline \multirow[t]{4}{*}{ Th1 } & $\mid \mathrm{L}-12$ & $0.18(0.16)$ & 0.259 & $0.34(0.14)$ & 0.015 & $0.30(0.17)$ & 0.074 & $0.30(0.27)$ & 0.276 \\
\hline & IL-2 & $0.12(0.07)$ & 0.092 & $0.15(0.06)$ & 0.019 & $0.14(0.08)$ & 0.081 & $0.09(0.12)$ & 0.448 \\
\hline & IL-2R & $0.16(0.10)$ & 0.103 & $0.23(0.09)$ & 0.012 & $0.19(0.11)$ & 0.081 & $0.15(0.18)$ & 0.398 \\
\hline & IFN- $\gamma$ & $0.18(0.12)$ & 0.137 & $0.29(0.11)$ & 0.008 & $0.25(0.13)$ & 0.056 & $-0.03(0.21)$ & 0.898 \\
\hline Th2 & IL-13 & $0.14(0.13)$ & 0.272 & $0.25(0.12)$ & 0.031 & $0.25(0.14)$ & 0.079 & $0.26(0.22)$ & 0.237 \\
\hline \multirow[t]{3}{*}{ Chemokines } & MIP-1a & $0.47(0.27)$ & 0.085 & $0.72(0.25)$ & 0.004 & $0.59(0.30)$ & 0.049 & $0.57(0.48)$ & 0.237 \\
\hline & MIP-1 $\beta$ & $0.36(0.25)$ & 0.143 & $0.56(0.22)$ & 0.013 & $0.52(0.26)$ & 0.049 & $0.54(0.43)$ & 0.214 \\
\hline & RANTES & $0.17(0.10)$ & 0.097 & $0.23(0.09)$ & 0.015 & $0.21(0.11)$ & 0.062 & $0.07(0.18)$ & 0.697 \\
\hline \multirow[t]{5}{*}{ Growth factors } & EGF & $0.10(0.06)$ & 0.087 & $0.12(0.05)$ & 0.017 & $0.09(0.06)$ & 0.125 & $0.09(0.10)$ & 0.360 \\
\hline & FGF & $0.16(0.09)$ & 0.069 & $0.22(0.08)$ & 0.005 & $0.23(0.09)$ & 0.017 & $0.32(0.15)$ & 0.037 \\
\hline & G-CSF & $0.18(0.13)$ & 0.170 & $0.35(0.12)$ & 0.004 & $0.29(0.14)$ & 0.047 & $0.38(0.23)$ & 0.099 \\
\hline & GM-CSF & $0.34(0.16)$ & 0.033 & $0.53(0.14)$ & $<0.001$ & $0.36(0.17)$ & 0.032 & $0.64(0.27)$ & 0.020 \\
\hline & HGF & $0.08(0.06)$ & 0.151 & $0.11(0.05)$ & 0.029 & $0.06(0.06)$ & 0.299 & $0.04(0.10)$ & 0.676 \\
\hline \multicolumn{10}{|c|}{ TLR9 responses using $\log _{10}$ of ratio cytokines concentrations } \\
\hline Th2 & IL-5 & $-0.08(0.07)$ & 0.283 & $-0.11(0.07)$ & 0.008 & $-0.20(0.08)$ & 0.009 & $-0.14(0.13)$ & 0.267 \\
\hline \multirow[t]{2}{*}{ Growth factors } & FGF & $0.08(0.07)$ & 0.231 & $0.14(0.06)$ & 0.028 & $0.15(0.07)$ & 0.050 & $0.14(0.12)$ & 0.234 \\
\hline & G-CSF & $0.11(0.08)$ & 0.187 & $0.17(0.07)$ & 0.016 & $0.15(0.09)$ & 0.082 & $0.09(0.09)$ & 0.505 \\
\hline \multicolumn{10}{|c|}{ TLR3 responses using $\log _{10}$ of ratio cytokines concentrations } \\
\hline Th2 & IL-5 & $-0.06(0.06)$ & 0.392 & $-0.12(0.06)$ & 0.046 & $-0.15(0.07)$ & 0.033 & $-0.02(0.11)$ & 0.841 \\
\hline Chemokines & IP-10 & $0.13(0.11)$ & 0.222 & $0.22(0.10)$ & 0.026 & $0.32(0.12)$ & 0.008 & $0.10(0.19)$ & 0.584 \\
\hline \multicolumn{10}{|c|}{ Unstimulated samples using $\log _{10}$ of crude cytokines concentrations } \\
\hline \multirow[t]{4}{*}{ Pro } & IFN-a & $-0.11(0.07)$ & 0.154 & $-0.14(0.07)$ & 0.038 & $-0.15(0.08)$ & 0.069 & $-0.01(0.13)$ & 0.948 \\
\hline & IL-1RA & $-0.24(0.12)$ & 0.055 & $-0.23(0.11)$ & 0.040 & $-0.23(0.14)$ & 0.086 & $-0.37(0.21)$ & 0.084 \\
\hline & $\| L-1 \beta$ & $-0.35(0.24)$ & 0.152 & $-0.58(0.22)$ & 0.008 & $-0.50(0.26)$ & 0.057 & $-0.62(0.42)$ & 0.142 \\
\hline & TNF & $-0.40(0.26)$ & 0.117 & $-0.61(0.23)$ & 0.009 & $-0.49(0.28)$ & 0.079 & $-0.47(0.45)$ & 0.296 \\
\hline \multirow[t]{2}{*}{ Anti } & IL-10 & $-0.22(0.32)$ & 0.485 & $-0.60(0.29)$ & 0.041 & $-0.45(0.35)$ & 0.204 & $-0.92(0.56)$ & 0.105 \\
\hline & IL-7 & $-0.34(0.10)$ & $<0.001$ & $-0.40(0.09)$ & $<0.001$ & $-0.35(0.11)$ & $<0.001$ & $-0.40(0.17)$ & 0.021 \\
\hline \multirow[t]{3}{*}{ Th1 } & IL-15 & $-0.39(0.16)$ & 0.015 & $-0.52(0.14)$ & $<0.001$ & $-0.52(0.17)$ & 0.003 & $-0.36(0.28)$ & 0.190 \\
\hline & $\mid \mathrm{L}-2$ & $-0.15(0.08)$ & 0.064 & $-0.16(0.07)$ & 0.032 & $-0.18(0.09)$ & 0.053 & $-0.12(0.14)$ & 0.382 \\
\hline & IFN- $\gamma$ & $-0.14(0.08)$ & 0.094 & $-0.17(0.07)$ & 0.023 & $-0.21(0.09)$ & 0.024 & $-0.10(0.14)$ & 0.494 \\
\hline \multirow[t]{2}{*}{ Th2 } & IL-13 & $-0.25(0.12)$ & 0.038 & $-0.22(0.11)$ & 0.042 & $-0.32(0.13)$ & 0.014 & $-0.12(0.21)$ & 0.056 \\
\hline & IL-4 & $-0.27(0.14)$ & 0.057 & $-0.40(0.13)$ & 0.002 & $-0.26(0.15)$ & 0.096 & $-0.07(0.25)$ & 0.769 \\
\hline Th17 & IL-17 & $-0.13(0.07)$ & 0.046 & $-0.15(0.06)$ & 0.016 & $-0.17(0.07)$ & 0.017 & $-0.18(0.12)$ & 0.128 \\
\hline \multirow[t]{2}{*}{ Chemokines } & MIP-1a & $-0.29(0.28)$ & 0.297 & $-0.56(0.25)$ & 0.029 & $-0.50(0.31)$ & 0.102 & $-0.37(0.49)$ & 0.453 \\
\hline & RANTES & $-0.23(0.12)$ & 0.050 & $-0.25(0.11)$ & 0.023 & $-0.28(0.13)$ & 0.029 & $-0.19(0.21)$ & 0.371 \\
\hline \multirow[t]{2}{*}{ Growth factors } & EGF & $-0.11(0.07)$ & 0.106 & $-0.12(0.06)$ & 0.047 & $-0.15(0.07)$ & 0.049 & $-0.09(0.12)$ & 0.446 \\
\hline & FGF & $-0.12(0.08)$ & 0.151 & $-0.15(0.08)$ & 0.049 & $-0.17(0.09)$ & 0.070 & $-0.17(0.15)$ & 0.244 \\
\hline
\end{tabular}


Table 2 Multivariable linear regression analyses assessing the effect of prenatal malaria exposure (PME) categories on TLR-mediated cytokine responses at birth (Continued)

\begin{tabular}{|c|c|c|c|c|c|c|c|c|c|}
\hline \multirow[t]{2}{*}{ Cytokines* } & & \multicolumn{2}{|c|}{ Exposed/no PM vs non-exposed } & \multicolumn{2}{|c|}{ Past PM vs non-exposed } & \multicolumn{2}{|c|}{ Chronic PM vs non-exposed } & \multicolumn{2}{|c|}{ Acute PM vs non-exposed } \\
\hline & & Coeff (SE) & $P$ & Coeff (SE) & $P$ & Coeff (SE) & $P$ & Coeff (SE) & $P$ \\
\hline & G-CSF & $-0.21(0.17)$ & 0.229 & $-0.37(0.15)$ & 0.019 & $-0.37(0.15)$ & 0.045 & $-0.33(0.30)$ & 0.276 \\
\hline & GM-CSF & $-0.36(0.19)$ & 0.058 & $-0.59(0.17)$ & $<0.001$ & $-0.60(0.21)$ & 0.004 & $-0.59(0.33)$ & 0.079 \\
\hline & HGF & $-0.19(0.07)$ & 0.008 & $-0.20(0.06)$ & 0.002 & $-0.19(0.08)$ & 0.015 & $-0.15(0.12)$ & 0.221 \\
\hline & VEGF & $-0.45(0.22)$ & 0.041 & $-0.59(0.20)$ & 0.003 & $-0.43(0.24)$ & 0.070 & $-0.35(0.38)$ & 0.356 \\
\hline
\end{tabular}

PM placental malaria, Coeff coefficient, SE standard error, Pro proinflammatory cytokines, $P p$ value, Anti anti-inflammatory cytokines, Th1 Th1-type cytokines, Th2 Th2-type cytokines, Th17 Th17, type cytokines. *Only cytokines whose concentrations are significantly modified by categories of PME are presented. Non-exposed category was used as reference in each model. Significant results are shown in italic

placenta is associated with the maturation of cord blood myeloid and plasmocytoid DCs (innate immune cells triggered by TLR7/8 agonists $[11,30])$, which may explain why cytokine responses to TLR7/8 stimulation were significantly enhanced in past PM (as well as in chronic PM, although with modest significance possibly due to the smaller sample size) compared to the other PME categories. A number of studies have also explored the effect of in utero malaria exposure on cord blood immune cell populations including dendritic cells (DCs), $\gamma \delta$ T cells, CD4 ${ }^{+} \mathrm{T}$ regulatory, and effector cells [10-15]. Interestingly, all revealed a varying effect of PME categories on cord blood mononuclear cells, thus ultimately demonstrating inter-individual variation in immune responses following different types of PME. Consequently, the differential admixture of cell types across PME categories may be explanatory of the observed differences in cytokine production in the present study. In addition, there is increasing evidence that the innate system has immunological memory [50-54] and that innate stimulations can lead to sensitization to following pathogen exposure, a process termed trained innate immunity [53]. Therefore, in utero exposure could affect TLR responses of cord blood cells through the development of trained immunity.

While TLR7/8 stimulation induced robust cytokine responses, overall cytokine responses induced by TLR3 and TLR9 stimulations were low with limited variations between PME categories, consistent with previous investigations in African children [30, 55, 56] and non-African children $[57,58]$. Although TLR3 and TLR9 are endosomal PRRs like TLR7/8, they differ in their responses depending on the cell populations, which may
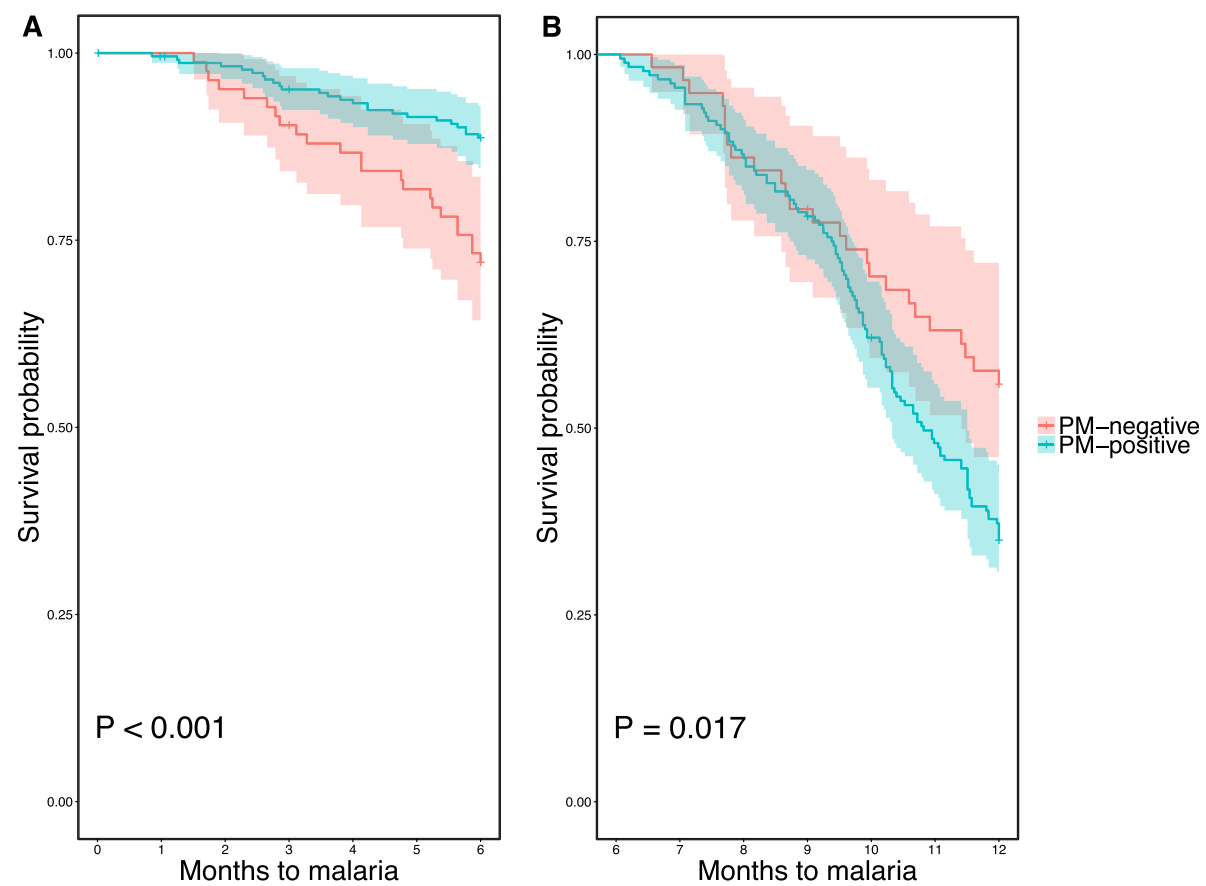

Fig. 3 Risk of clinical malaria during the first year of life, by prenatal malaria exposure (placental malaria versus no placental malaria). Kaplan-Meier survival curves (including 95\% confidence intervals) stratified by infants born to mothers with (blue line) or without (red line) PM. a Clinical malaria episodes during the first 6 months of life. $\mathbf{b}$ Clinical malaria episodes from 6 to 12 months of life. $P$ values were determined by log-rank test 


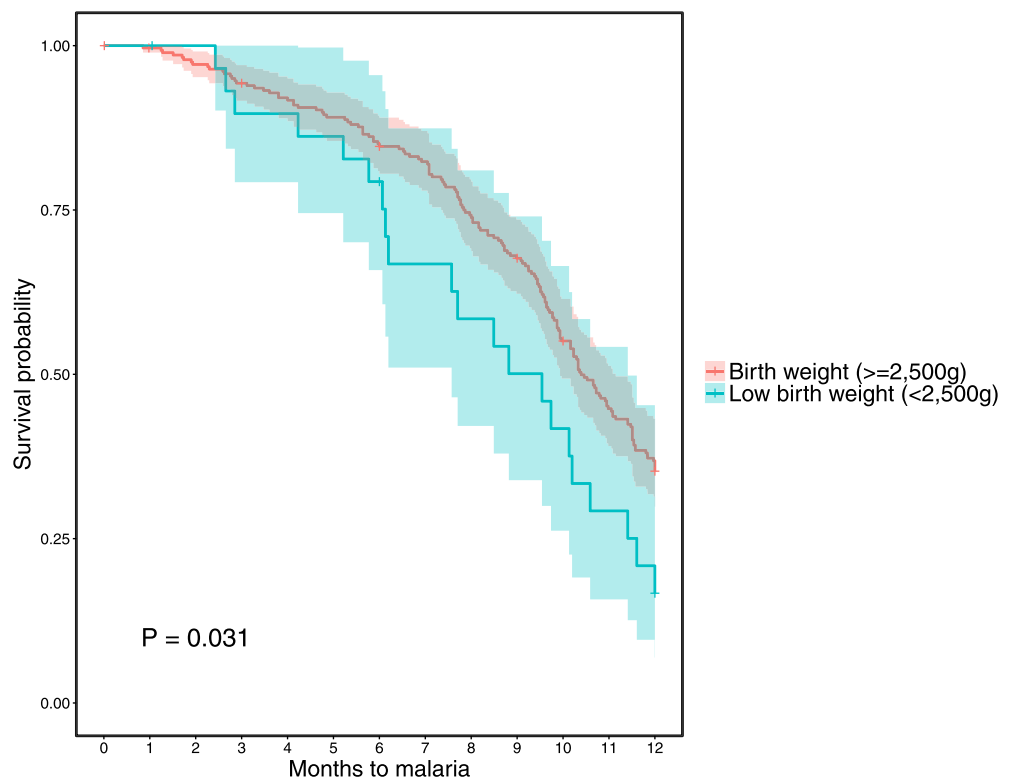

Fig. 4 Risk of clinical malaria during the first year of life, by birth weight. Kaplan-Meier survival curves (including 95\% confidence intervals) stratified by infants born with a birth weight $\geq 2500 \mathrm{~g}$ (red line) and with a birth weight below $2500 \mathrm{~g}$ (low birth weight, blue line). $P$ value was determined by log-rank test

explain differences in their inducible capacity of cytokine responses. Importantly, spontaneous cytokine production by cord blood cells in unstimulated samples also displayed significant variations between PME groups, with a trend towards decreased baseline levels in infants born to mothers with peripheral infection to those born to mothers with PM (past, chronic, and acute PM, respectively). Altogether, our findings are consistent with the hypothesis that PME results in a downregulation of cytokines production that can affect all the important functional classes of cytokines, but followed by a hyper-responsiveness to particular PRR agonists, such as TLR7/8 agonist, as compared to that in non-exposed infants.

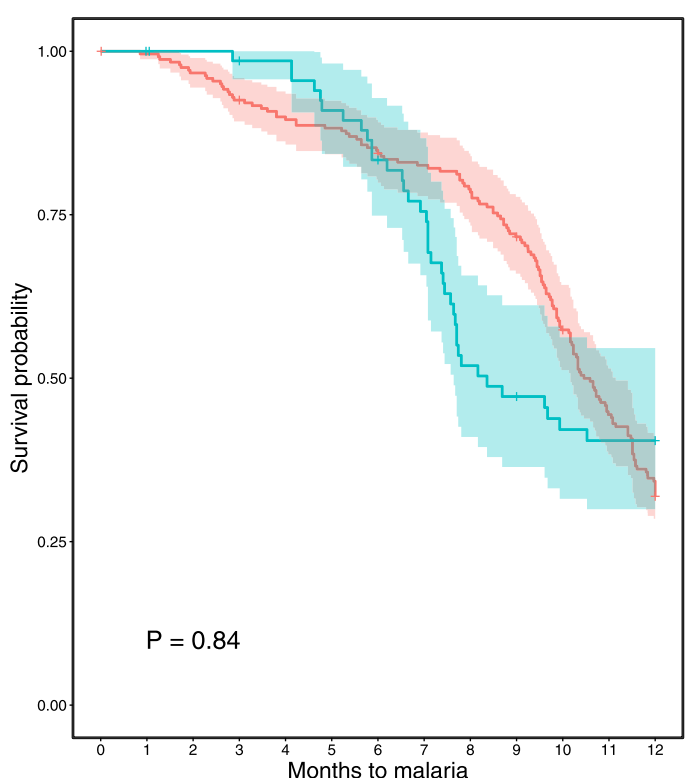

- High-transmission season + Low-transmission season

Fig. 5 Risk of clinical malaria during the first year of life, by birth season. Kaplan-Meier survival curves (including 95\% confidence intervals) stratified by infants born during malaria high-transmission season (July-December, red line) and low-transmission season (January-June, blue line). $P$ value was determined by log-rank test 
Table 3 Cox proportional hazards analyses assessing the association between TLR-induced cytokine responses and the risk of malaria during the first year of life. Adjusted hazard ratio and $95 \% \mathrm{Cl}$ for each model is shown

\begin{tabular}{|c|c|c|c|c|c|c|c|c|}
\hline \multicolumn{2}{|l|}{ Cytokines** } & \multirow{3}{*}{$\begin{array}{l}\text { Unstimulated } \\
\text { Crude } \\
\text { AHR ( } 95 \% \mathrm{Cl})\end{array}$} & \multicolumn{2}{|l|}{ TLR3 responses } & \multicolumn{2}{|l|}{ TLR7/8 responses } & \multicolumn{2}{|l|}{ TLR9 responses } \\
\hline & & & \multirow{2}{*}{$\begin{array}{l}\text { Crude } \\
\text { AHR }(95 \% \mathrm{Cl})\end{array}$} & \multirow{2}{*}{$\begin{array}{l}\text { Ratios } \\
\text { AHR (95\% Cl) }\end{array}$} & \multirow{2}{*}{$\begin{array}{l}\text { Crude } \\
\text { AHR (95\% Cl) }\end{array}$} & \multirow{2}{*}{$\begin{array}{l}\text { Ratios } \\
\text { AHR (95\% Cl) }\end{array}$} & \multirow{2}{*}{$\begin{array}{l}\text { Crude } \\
\text { AHR }(95 \% \mathrm{Cl})\end{array}$} & \multirow{2}{*}{$\begin{array}{l}\text { Ratios } \\
\text { AHR (95\% Cl) }\end{array}$} \\
\hline & & & & & & & & \\
\hline \multirow[t]{4}{*}{ Pro } & IFN-a & & & $0.24(0.05-1.10)$ & & & & \\
\hline & IL-1RA* & & & & $0.61(0.36-1.03)$ & $0.70(0.50-0.98)$ & & \\
\hline & $\| L-1 \beta$ & $1.16(0.98-1.37)$ & $1.15(0.97-1.36)$ & & & & $1.18(1.01-1.39)$ & \\
\hline & TNF & & & & & & & \\
\hline \multirow[t]{2}{*}{ Anti } & $\| L-10$ & & $1.12(0.99-1.25)$ & & & & & \\
\hline & IL-7 & & $1.80(1.26-2.58)$ & $1.54(1.11-2.15)$ & & & & \\
\hline \multirow[t]{5}{*}{ Th1 } & IL-15 & & & & & & $1.22(0.96-1.54)$ & \\
\hline & $\mid \mathrm{L}-12^{*}$ & $1.28(0.97-1.69)$ & $1.26(0.95-1.68)$ & $0.27(0.07-1.15)$ & & $0.76(0.59-0.98)$ & & $0.46(0.20-1.04)$ \\
\hline & IL-2 & & & & & & & \\
\hline & IL-2R & & & & & & & \\
\hline & IFN- $\gamma$ & & & & & & & \\
\hline \multirow[t]{3}{*}{ Th2 } & IL-13 & & & & & & & \\
\hline & IL-5 & & & & & & & \\
\hline & $\mid \mathrm{L}-4$ & & & & & & & \\
\hline \multirow[t]{2}{*}{ Th17 } & IL-17 & & & & & & & \\
\hline & IL-6 & & & & & & & \\
\hline \multirow[t]{8}{*}{ Chemokines } & |L-8 & & & & & & & \\
\hline & $\mid \mathrm{P}-10^{*}$ & $0.64(0.38-1.08)$ & $0.66(0.46-0.93)$ & & & & $0.75(0.59-0.96)$ & \\
\hline & MCP-1 & & & & & & & \\
\hline & MIG & & & & & & & $0.77(0.56-1.05)$ \\
\hline & MIP-1a & & & & & & $1.13(0.97-1.31)$ & \\
\hline & MIP-1 $\beta$ & & & & & & & \\
\hline & RANTES & & & & & & & \\
\hline & EOTAXIN & $1.83(1.11-3.01)$ & $1.60(0.99-2.58)$ & $0.19(0.03-1.14)$ & $1.72(1.01-2.94)$ & & & $0.46(0.24-0.86)$ \\
\hline \multirow[t]{6}{*}{ Growth factors } & EGF & & & & $0.29(0.08-1.07)$ & & & \\
\hline & FGF & & $1.63(0.91-2.93)$ & & & & & \\
\hline & G-CSF & $1.24(0.97-1.57)$ & & & & & & \\
\hline & GM-CSF* & & & & $1.28(1.01-1.15)$ & & & \\
\hline & HGF & & & & & & & \\
\hline & VEGF & & & & & & & \\
\hline
\end{tabular}

HR hazard ratio, $\mathrm{Cl}$ confidence interval, Pro proinflammatory cytokines, Anti anti-inflammatory cytokines, Th1 Th1-type cytokines, Th2 Th2-type cytokines, Th17 Th17-type cytokines. **Only results of cox proportional analysis for cytokines with $P$ value $(P) \leq 0.100$ are presented. ${ }^{*}$ Cytokines whose levels were significantly modified by prenatal malaria exposure categories. Significant results are shwon in italic

Innate immune activation plays a crucial role in host protection as well as pathogenesis during malaria infection $[59,60]$. Therefore, the second important aim of our study was to determine the predictive value of cytokines that were significantly influenced by PME for clinical malaria occurrence during the first year of life. Of note, we have shown that PME has a clinical impact on the risk of malaria among the study population. Indeed, we observed that infants born to mothers with PM had a lower risk of clinical malaria during the first 6 months of life, in contrast to that reported in several epidemiological studies $[2,4,5,7]$. This paradoxal finding may be at least partially explained by the protective effect of maternal antibodies and the strong malaria seasonality of the study area [39], which may make PME dynamics different from other sites. However, we cannot exclude a confounding or explanatory effect of other factors not assessed in this study.

Notably, we observed that some cytokines, which were associated with PME, were independent predictors of malaria risk or protection, demonstrating the clinical relevance 
of the modulation of infants' innate immune responses by PME. However, few studies have investigated the predictive value of cytokines, measured at birth either in unstimulated samples $[49,61]$ or upon stimulation with TLR [30], on the risk of clinical malaria during infancy. Those studies showed a protective prediction of high proinflammatory cytokine levels in unstimulated samples (TNF, TNF-RI, IL-1 $\beta$ ), while high levels of anti-inflammatory cytokines such as IL-10 (upon TLR3 and TLR7/8 stimulations) predicted an increased risk of clinical malaria in early childhood $[30,49,61]$. Here, we found that Th1 cytokines and chemokines (IL-12 TLR7/8 ratio and IP-10 TLR3 crude) and cytokines induced upon inflammation (IL-1RA TLR7/8 ratio) were associated with a decreased risk of clinical malaria during the first year of life. These results are in agreement with a key role of IL-12 in the induction of a Th1-type protective immunity against malaria mediated by IFN- $\gamma$, TNF, and nitric oxide productions [62-66] and the inhibiting effect on disease severity of IL-1RA on IL-1A and IL-1 $\beta$ (through binding to IL-1 receptors) [67]. For IP-10, a cytokine belonging to the CXC chemokine family that induces chemotaxis, apoptosis, cell growth, and angiostasis, the association with malaria protection observed in this study is in agreement with studies in the murine model [68], although in contrast with others that have shown an association with clinical malaria and disease severity [6972]. Among biomarkers that were significantly associated with PME, GM-CSF TLR7/8 crude was associated with a risk of developing clinical malaria during the first year of life, which is in contrast with previous observations [7375], but in agreement with others [76]. These conflicting findings could be related to the fact that cytokines promoting a protective inflammatory environment during malaria infection could become harmful if exaggerated and act in favor of disease manifestation [77-79]. Overall, these results suggest that PME has an impact on malaria risk and that the effect is at least partially mediated by the modulation of TLR and the consequent cytokine responses. Given that past PM, which potentially occurs early during pregnancy, has a profound effect on fetal immune system, a strategy based on screening and treatment of malaria during pregnancy that we proved to benefit infants [40] should be implemented as early as possible during the first trimester.

In this study, two main limitations should be noted. First, some of the PME groups including acute PM and non-exposed groups were small in comparison with others. Therefore, we cannot exclude an underestimation of the effect of acute PM on innate immune responses measured. However, this number reflects the prevalence of PM categories in the main COSMIC trial as most of malaria infections in the placenta were past or chronic PM (95.5\%). The relatively limited number of non-exposed controls is due to the high malaria transmission in the study area and the strict definition and recruitment that we applied to this group, where pregnant women had negative RDT/LM and $\mathrm{qPCR}$ results at each screening and ANC visit, in addition to negative placental histology. Second, in this study, the measurement of white blood cells population and lymphocyte subsets in cord blood at delivery was not performed while there is evidence that PME can alter myeloid subsets abundance and thus influence TLR-mediated innate immune responses. Therefore, the lack of these information has eventually limited the interpretation of our data.

\section{Conclusions}

In conclusion, despite these limitations, our findings indicate that the various PME categories have different effects on innate immune responses of the newborn at birth, which might drive variation between individuals to malaria susceptibility during the first year of life. The differential alteration of TLR-mediated immune responses by PME categories may have profound implications on immune responses to other infections as well as to vaccines formulated with TLR-based adjuvants in infants prenatally exposed to malaria.

\section{Additional files}

\section{Additional file 1: Boxplots showing variation in cytokine responses by stimulation. Figure S1. Boxplots generated using $\log _{10}$ of crude concentrations (pg/mL). Figure S2. Boxplots generated using $\log _{10}$ of ratios (TLR/unstimulated). (PDF $287 \mathrm{~kb}$ ) \\ Additional file 2: Changes in cytokine responses according to prenatal malaria exposure categories. Figure S3. Boxplots generated using $\log _{10}$ of unstimulated crude concentrations (pg/mL). Figure S4. Boxplots generated using $\log _{10}$ of TLR3/unstimulated ratio. Figure S5. Boxplots generated using $\log _{10}$ of TLR7/8/unstimulated ratio; Figure S6. Boxplots generated using $\log _{10}$ of TLR9/unstimulated ratio. Non-expo, non- exposed; expo-no-PM, exposed/no placental malaria; past PM, past placental malaria; chronic-PM, chronic placental malaria; acute PM, acute placental malaria. (PDF $350 \mathrm{~kb}$ )}

Additional file 3: Table S1. Variables included in the linear regression models assessing the effect of prenatal malaria exposure on TLRmediated cytokine responses at birth. (PDF $88 \mathrm{~kb}$ )

\section{Abbreviations}

AL: Artemether-lumefantrine; ANC: Antenatal care; COSMIC: Communitybased scheduled screening and treatment of malaria in pregnancy: a cluster randomized trial; CSST/IPTP-SP: Community-based scheduled screening and treatment of malaria in combination with intermittent preventive treatment with sulfadoxine-pyrimethamine; EGF: Epidermal growth factor; FGF: Fibroblast growth factor; G-CSF: Granulocyte-colony stimulating factor; GM-CSF: Granulocyte-macrophage colony stimulating factor; HGF: Hepatocyte growth factor; IFN: Interferon; IL: Interleukin; IP: IFN- - -inducible protein; IPTp-SP: intermittent preventive treatment during pregnancy with sulfadoxine-pyrimethamine; ITN: Insecticide-treated net; LBW: Low birth weight; LM: Light microscopy; MCP: Monocyte chemottractant protein; MIG: Monokine induced by IFN- $\gamma$; MIP: Macrophage inflammatory protein; MiP: malaria in pregnancy; PAMPs: Pathogen-associated-molecular patterns; PM: Placental malaria; PME: Prenatal malaria exposure; PRRs: Pattern recognition receptors; qPCR: Quantitative real-time polymerase chain reaction; RDT: Rapid diagnostic test; TLRs: Toll-like receptors; TNF: Tumor necrosis factor; VEGF: Vascular endothelial growth factor 


\section{Acknowledgements}

We are sincerely grateful to the mothers and their offspring for participating into this study. We are indebted to nurses, field workers, field supervisors, data managers, and laboratory workers at the Clinical Research Unit of Nanoro (CRUN) in Burkina Faso for their valuable contribution to the successful completion of the study. We also acknowledge the research teams at the Malariology Unit, Institute of Tropical Medicine (ITM; Belgium), the Immunology Laboratory at the Manhiça Health Research Center (Mozambique), and the malaria laboratory at ISGlobal, Spain.

\section{Funding}

The study was supported by the Belgium Directorate General for Development Cooperation (DGD) through the collaborative framework agreement 3 (FA3-DGD programme) between CRUN (Burkina Faso) and ITM (Belgium); the COSMIC project funded by European Union Seventh Framework Programme (FP7/2002-2016) under grant agreement no. 305662 COSMIC); the Research Foundation-Flanders (FWO) long (V4.675.15N) and short (K2.090.17N) stay abroad travel grants. HMN holds a PhD fellowship funded by DGD.

\section{Availability of data and materials}

All data generated or analyzed during this study are included in this published article and its supplementary information files.

\section{Authors' contributions}

HMN, GM, ERV, CD, and ARU conceived and designed the study. HMN, HSo, MTC, MAS, SS, and IV supervised the data and samples collection in the field. HMN, HSO, MTC, and MAS supervised the malaria diagnosis and management of malaria patients in the field. HMN performed the TLR-mediated stimulation assay and Pf-varATS qPCR experiments. HMN and RA performed the cytokines quantification experiments. IV, PFM, HDFHS, HT, LK, CD, and ARU contributed for the reagents/materials/analysis tools. HMN, HSa, GM, ERV, RA, CD, and ARU analyzed and interpreted the results and were the major contributors in writing the manuscript. All authors read and approved the final manuscript

\section{Ethics approval and consent to participate}

This study was approved by the institutional ethics committees of Centre Muraz in Burkina Faso (006-2014/CE-CM), the Institute of Tropical Medicine in Belgium (953/14), and the University Hospital in Antwerp (UZA) in Belgium (14/26/277). Written informed consent was obtained from all mothers.

\section{Consent for publication}

Not applicable.

\section{Competing interests}

The authors declare that they have no competing interests.

\section{Publisher's Note}

Springer Nature remains neutral with regard to jurisdictional claims in published maps and institutional affiliations.

\section{Author details}

${ }^{1}$ Department of Biomedical Sciences, Institute of Tropical Medicine, B 2000 Antwerp, Belgium. ${ }^{2}$ Unité de Recherche Clinique de Nanoro, Institut de Recherche en Sciences de la Santé, BP218, Nanoro, Burkina Faso.

${ }^{3}$ Department of Biomedical Sciences, University of Antwerp, B 2610 Antwerp, Belgium. ${ }^{4}$ Barcelona Institute for Global Health (ISGlobal), Hospital Clinic Universitat de Barcelona, Carrer Rossello 132, E-08036 Barcelona, Catalonia, Spain. ${ }^{5}$ Department of Epidemiology and Population Health, London School of Hygiene and Tropical Medicine, London WC1E7HT, UK. ${ }^{6}$ Department of Medical Microbiology - Parasitology Unit, Academic Medical Centre, Amsterdam 1105, AZ, The Netherlands. ${ }^{7}$ Centre Muraz, BP390, Bobo Dioulasso, Burkina Faso.

Received: 21 March 2018 Accepted: 5 October 2018

\section{Published online: 02 November 2018}

\section{References}

1. Le Hesran JY, Cot M, Personne P, Fievet N, Dubois B, Beyemé M, et al. Maternal placental infection with Plasmodium falciparum and malaria morbidity during the first 2 years of life. Am J Epidemiol. 1997;146:826-31.
2. Le Port A, Watier L, Cottrell G, Ouédraogo S, Dechavanne C, Pierrat C, et al. Infections in infants during the first 12 months of life: role of placental malaria and environmental factors. PLoS One. 2011;6:e27516.

3. Malhotra I, Dent A, Mungai P, Wamachi A, Ouma JH, Narum DL, et al. Can prenatal malaria exposure produce an immune tolerant phenotype? A prospective birth cohort study in Kenya. PLoS Med. 2009;6:e1000116.

4. Mutabingwa TK, Bolla MC, Li J-L, Domingo GJ, Li X, Fried M, et al. Maternal malaria and gravidity interact to modify infant susceptibility to malaria. PLoS Med. 2005;2:e407.

5. Schwarz NG, Adegnika AA, Breitling LP, Gabor J, Agnandji ST, Newman RD, et al. Placental malaria increases malaria risk in the first 30 months of life. Clin Infect Dis. 2008;47:1017-25.

6. Rachas A, Le PA, Cottrell G, Guerra J, Choudat I, Bouscaillou J, et al. Placental malaria is associated with increased risk of nonmalaria infection during the first 18 months of life in a Beninese population. Clin Infect Dis. 2012:55:672-8.

7. Sylvester B, Gasarasi DB, Aboud S, Tarimo D, Massawe S, Mpembeni R, et al. Prenatal exposure to Plasmodium falciparum increases frequency and shortens time from birth to first clinical malaria episodes during the first two years of life: prospective birth cohort study. Malar J. 2016;15:379.

8. Broen K, Brustoski K, Engelmann I, Luty AJF. Placental Plasmodium falciparum infection: causes and consequences of in utero sensitization to parasite antigens. Mol Biochem Parasitol. 2007;151:1-8.

9. Ismaili J, Van Der Sande M, Holland MJ, Sambou I, Keita S, Allsopp C, et al. Plasmodium falciparum infection of the placenta affects newborn immune responses. Clin Exp Immunol. 2003;133:414-21.

10. Engelmann I, Santamaria A, Kremsner PG, Luty AJF. Activation status of cord blood gamma delta T cells reflects in utero exposure to Plasmodium falciparum antigen. J Infect Dis. 2005;191:1612-22.

11. Fievet N, Varani S, Ibitokou S, Briand V, Louis S, Perrin RX, et al. Plasmodium falciparum exposure in utero, maternal age and parity influence the innate activation of foetal antigen presenting cells. Malar J. 2009;8:251.

12. Flanagan $\mathrm{KL}$, Halliday $\mathrm{A}$, Burl $\mathrm{S}$, Landgraf $\mathrm{K}$, Jagne $\mathrm{YJ}$, Noho-Konteh F, et al. The effect of placental malaria infection on cord blood and maternal immunoregulatory responses at birth. Eur J Immunol. 2010:40:1062-72.

13. Prahl M, Jagannathan $P$, Mclntyre Tl, Auma A, Farrington L, Wamala $S$, et al. Timing of in utero malaria exposure influences fetal CD4 T cell regulatory versus effector differentiation. Malar J. 2016;15:497.

14. Brustoski K, Mo U, Kramer M, Petelski A, Brenner S, Palmer DR, et al. IFN-g_ and IL-10 mediate parasite-specific immune responses of cord blood cells induced by pregnancy-associated Plasmodium falciparum malaria. J Immunol. 2005;174:1738-45.

15. Breitling LP, Fendel R, Mordmueller B, Adegnika A a, Kremsner PG, Luty AJF. Cord blood dendritic cell subsets in African newborns exposed to Plasmodium falciparum in utero. Infect Immun. 2006;74:5725-9.

16. King CL, Malhotra I, Wamachi A, Kioko J, Mungai P, Wahab SA, et al. Acquired immune responses to Plasmodium falciparum merozoite surface protein-1 in the human fetus. J Immunol. 2002;168:356-64.

17. Metenou S, Suguitan AL, Long C, Leke RGF, Taylor DW. Fetal immune response to Plasmodium falciparum antigens in a malaria-endemic region of Cameroon. J Immunol. 2007;178:2770-7.

18. Xi G, Leke RGF, Thuita LW, Zhou A, Leke RJl, Mbu R, et al. Congenital exposure to Plasmodium falciparum Antigens: prevalence and antigenic specificity of in utero-produced antimalarial immunoglobulin $\mathrm{M}$ antibodies. Infect Immun. 2003;71:1242-6.

19. Dent A, Malhotra I, Mungai P, Muchiri E, Crabb BS, Kazura JW, et al. Prenatal malaria immune experience affects acquisition of Plasmodium falciparum Merozoite surface Protein-1 invasion inhibitory antibodies during infancy. J Immunol. 2006;177:7139-45.

20. Malhotra I, Mungai P, Muchiri E, Ouma J, Sharma S, Kazura JW, et al. Distinct Th1- and Th2-type prenatal cytokine responses to Plasmodium falciparum erythrocyte invasion ligands. Infect Immun. 2005;73:3462-70.

21. Maródi L. Innate cellular immune responses in newborns. Clin Immunol. 2006;1 18:137-44.

22. Levy O. Innate immunity of the newborn: basic mechanisms and clinical correlates. Nat Rev Immunol. 2007;7:379-90.

23. Staros EB. Innate immunity: new approaches to understanding its clinical significance. Am J Clin Pathol. 2005;123:305-12.

24. Takeda K, Akira S. Toll-like receptors in innate immunity. Int Immunol. 2005; 17:1-14.

25. Iwasaki A, Medzhitov R. Toll-like receptor control of the adaptive immune responses. Nat Immunol. 2004;5:987-95. 
26. Maródi L. Neonatal innate immunity to infectious agents. Infect Immun. 2006;74:1999-2006.

27. Erdman LK, Finney CAM, Liles WC, Kain KC. Inflammatory pathways in malaria infection: TLRs share the stage with other components of innate immunity. Mol Biochem Parasitol. 2008;162:105-11.

28. Angulo I, Fresno M. Cytokines in the pathogenesis of and protection against malaria. Clin Diagn Lab Immunol. 2002;9:1145-52.

29. Adegnika AA, Köhler C, Agnandji ST, Chai SK, Labuda L, Breitling LP, et al. Pregnancy-associated malaria affects toll-like receptor ligand-induced cytokine responses in cord blood. J Infect Dis. 2008;198:928-36.

30. Gbédandé K, Varani S, Ibitokou S, Houngbegnon P, Borgella S, Nouatin O, et al. Malaria modifies neonatal and early-life toll-like receptor cytokine responses. Infect Immun. 2013;81:2686-96.

31. Coban C, Ishii KJ, Kawai T, Hemmi H, Sato S, Uematsu S, et al. Toll-like receptor 9 mediates innate immune activation by the malaria pigment hemozoin. J Exp Med. 2005;201:19-25

32. Gazzinelli RT, Kalantari P, Fitzgerald KA, Golenbock DT. Innate sensing of malaria parasites. Nat Rev Immunol. 2014;14(11):744-57.

33. Zhu J, Krishnegowda G, Gowda DC. Induction of proinflammatory responses in macrophages by the glycosylphosphatidylinositols of Plasmodium falciparum. J Biol Chem. 2005;280:8617-27.

34. Eriksson EM, Sampaio NG, Schofield L. Toll-like receptors and malaria sensing and susceptibility. J Trop Dis. 2014;02:126.

35. Esposito S, Molteni CG, Zampiero A, Baggi E, Lavizzari A, Semino M, et al. Role of polymorphisms of toll-like receptor ( TLR ) containing adaptor protein (TIRAP) and FCGR2A genes in malaria susceptibility and severity in Burundian children. Malar J. 2012;11:196.

36. Omar AH, Shibata H, Yasunami M, Yamazaki A, Ofori MF, Hirayama K, et al. Toll-like receptor 9 (TLR9) polymorphism associated with symptomatic malaria: a cohort study. Malar J. 2012;11:168

37. Scott S, Mens PF, Tinto H, Nahum A, Ruizendaal E, Pagnoni F, et al. Community-based scheduled screening and treatment of malaria in pregnancy for improved maternal and infant health in the Gambia, Burkina Faso and Benin: study protocol for a randomized controlled trial. Trials. 2014;15:340

38. Derra K, Rouamba E, Kazienga A, Ouedraogo S, Tahita MC, Sorgho H, et al. Profile: Nanoro health and demographic surveillance system. Int J Epidemiol. 2012:41:1293-301.

39. Natama HM, Vallbona ER, Somé MA, Zango SH, Sorgho H, Guetens P, et al. Malaria incidence and prevalence during the first year of life in Nanoro, Burkina Faso: a birth-cohort study. Malar J. 2018;17:163.

40. Natama HM, Rovira-Vallbona E, Sorgho H, Somé MA, Traoré-Coulibaly M, Scott $\mathrm{S}$, et al. Additional screening and treatment of malaria during pregnancy provides further protection against malaria and nonmalarial fevers during the first year of life. J Infect Dis. 2018;217:1967-76.

41. Natama HM, Ouedraogo DF, Sorgho H, Rovira-Vallbona E, Serra-casas E, Somé MA, et al. Diagnosing congenital malaria in a high-transmission setting: clinical relevance and usefulness of $P$. falciparum HRP2-based testing. Sci Rep. 2017;7:2080.

42. Sanz H, Aponte J, Harezlak J, Dong Y, Ayestaran A, Nhabomba A, et al. drLumi: an open-source package to manage data, calibrate, and conduct quality control of multiplex bead-based immunoassays data analysis. PLoS One. 2017;12:e0187901

43. Defawe O, Fong Y, Vasilyeva E, Pickett M, Carter D, Gabriel E, et al. Optimization and qualification of a multiplex bead array to assess cytokine and chemokine production by vaccine-specific cells. J Immunol Methods. 2012;382:117-28

44. Gottschalk P, Dunn J. Determining the error of dose estimates and minimum and maximum acceptable concentrations from assays with nonlinear dose-response curves. Comput Methods Prog Biomed. 2005;80: 204-15.

45. Reed G, Lynn F, Meade B. Use of coefficient of variation in assessing variability of quantitative assays. Clin Diagn Lab Immunol. 2002;9:1235-9.

46. World Health Organization. In: WHO, editor. Basic malaria microscopy: part I. Learner's guide. 2nd ed; 2010. https://www.who.int/malaria/publications/ atoz/9241547820/en/. Accessed 10 Oct 2017.

47. R Core Team. R: a language and environment for statistical computing. $R$ Foundation for statistical computing, Vienna. 2016. https://www.r-project. org/. Accessed 3 Nov 2015.

48. Benjamini $Y$, Hochberg Y. Controlling the false discovery rate: a practical and powerful approach to multiple testing. J R Stat Soc. 1995;57:239-300.
49. Kabyemela E, Gonçalves BP, Prevots DR, Morrison R, Harrington W, Gwamaka M, et al. Cytokine profiles at birth predict malaria severity during infancy. PLoS One. 2013;8:e77214.

50. Netea MG, Quintin J, Van Der Meer JWM. Trained immunity: a memory for innate host defense. Cell Host Microbe. 2011;9(5):355-61.

51. Aaby P, Kollmann TR, Benn CS. Nonspecific effects of neonatal and infant vaccination: public-health, immunological and conceptual challenges. Nat Immunol. 2014;15:895-9.

52. Levy $\mathrm{O}$, Wynn J. A prime time for trained immunity: innate immune memory in newborns and infants. Neonatology. 2014;105:136-41.

53. Blok BA, Arts RJW, Van CR, Benn CS, Netea MG. Trained innate immunity as underlying mechanism for the long-term, nonspecific effects of vaccines. J Leukoc Biol. 2015:98:347-56.

54. Bauer $\mathrm{M}$, Weis $\mathrm{S}$, Netea M, Wetzker R. Remembering pathogen dose: longterm adaptation in innate immunity. Trends Immunol. 2018;39:438-45.

55. Burl S, Townend J, Njie-Jobe J, Cox M, Adetifa UJ, Touray E, et al. Agedependent maturation of toll-like receptor-mediated cytokine responses in Gambian infants. PLoS One. 2011;6:e18185.

56. Smolen KK, Ruck CE, Fortuno ES, Ho K, Dimitriu P, Mohn WW, et al. Pattern recognition receptor-mediated cytokine response in infants across 4 continents. J Allergy Clin Immunol. 2014;133:818-26.

57. Levy O, Suter EE, Miller RL, Wessels MR. Unique efficacy of toll-like receptor 8 agonists in activating human neonatal antigen-presenting cells. Blood. 2006;108:1284-90

58. Levy O, Zarember KA, Roy RM, Cywes C, Godowski PJ, Wessels MR. Selective impairment of TLR-mediated innate immunity in human newborns: neonatal blood plasma reduces monocyte TNF-alpha induction by bacterial lipopeptides, lipopolysaccharide, and imiquimod, but preserves the response to R-848. J Immunol. 2004;173:4627-34.

59. Frosch AEP, John CC. Immunomodulation in Plasmodium falciparum malaria: experiments in nature and their conflicting implications for potential therapeutic agents. Expert Rev Anti-Infect Ther. 2012:10:1343-56.

60. Dobbs KR, Embury P, Vulule J, Odada PS, Rosa BA, Mitreva M, et al. Monocyte dysregulation and systemic inflammation during pediatric falciparum malaria. JCl Insight. 2017;2:e95352.

61. Brickley EB, Wood AM, Kabyemela E, Morrison R, Kurtis JD, Fried M, et al. Fetal origins of malarial disease: cord blood cytokines as risk markers for pediatric severe malarial anemia. J Infect Dis. 2015;211:436-44.

62. Stevenson MM, Tam MF, Wolf SF, Sher A. IL-12-induced protection against blood-stage Plasmodium chabaudi AS requires IFN-gamma and TNF-alpha and occurs via a nitric oxide-dependent mechanism. J Immunol. 1995;155:2545-56.

63. Yoshimoto T, Yoneto T, Waki S, Nariuchi H. Interleukin-12-dependent mechanisms in the clearance of blood-stage murine malaria parasite Plasmodium berghei XAT, an attenuated variant of P. berghei NK65. J Infect Dis. 1998:177:1674-81.

64. Boutlis CS, Lagog M, Chaisavaneeyakorn S, Misukonis MA, Bockarie MJ, Mgone CS, et al. Plasma interleukin-12 in malaria-tolerant Papua New Guineans: inverse correlation with Plasmodium falciparum Parasitemia and peripheral blood mononuclear cell nitric oxide synthase activity. Infect Immun. 2003;71:6354-7.

65. Sarangi A, Mohapatra PC, Dalai RK, Sarangi AK. Serum IL-4, IL-12 and TNF-alpha in malaria: a comparative study associating cytokine responses with severity of disease from the coastal districts of Odisha. J Parasit Dis. 2014;38:143-7.

66. Luty AJF, Perkins DJ, Lell B, Schmidt-Ott R, Lehman LG, Luckner D, et al. Low interleukin-12 activity in severe Plasmodium falciparum malaria. Infect Immun. 2000:68:3909-15.

67. Berg A, Patel S, Gonca M, David C, Otterdal K, Ueland T, et al. Cytokine network in adults with falciparum malaria and HIV-1: increased IL-8 and IP10 levels are associated with disease severity. PLoS One. 2014;9:e1 14480.

68. Armah HB, Wilson NO, Sarfo BY, Powell MD, Bond VC, Anderson W, et al. Cerebrospinal fluid and serum biomarkers of cerebral malaria mortality in Ghanaian children. Malar J. 2007;6:147.

69. Jain V, Armah HB, Tongren JE, Ned RM, Wilson NO, Crawford S, et al. Plasma IP-10, apoptotic and angiogenic factors associated with fatal cerebral malaria in India. Malar J. 2008;7:83.

70. Liu M, Guo S, Hibbert JM, Jain V, Singh N, Wilson NO, et al. CXCL10/P-10 in infectious diseases pathogenesis and potential therapeutic implications. Cytokines Growth Factors Rev. 2011;22:121-30.

71. Hunt NH, Grau GE Cytokines: accelerators and brakes in the pathogenesis of cerebral malaria. Trends Immunol. 2003;24:491-9. 
72. Prakash D, Fesel C, Jain R, Cazenave P-A, Mishra GC, Pied S. Clusters of cytokines determine malaria severity in Plasmodium falciparum-infected patients from endemic areas of Central India. J Infect Dis. 2006;194:198-207.

73. Riopel J, Tam M, Mohan K, Marino MW, Stevenson MM. Granulocytemacrophage colony-stimulating factor-deficient mice have impaired resistance to blood-stage malaria. Infect Immun. 2001;69:129-36.

74. Weiss WR, Ishii KJ, Hedstrom RC, Sedegah M, Ichino M, Barnhart K, et al. A plasmid encoding murine granulocyte-macrophage colony-stimulating factor increases protection conferred by a malaria DNA vaccine. J Immunol. 1998;161:2325-32.

75. Moncunill G, Mpina M, Nhabomba AJ, Aguilar R, Ayestaran A, Sanz H, et al. Distinct helper T cell Type1 and 2 responses associated with malaria protection and risk in RTS,S/AS01E vaccinees. Clin Infect Dis. 2017;65:746-55.

76. Ringwald P, Peyron F, Vuillez JP, Touze JE, Le Bras J, Deloron P. Levels of cytokines in plasma during Plasmodium falciparum malaria attacks. J Clin Microbiol. 1991;29:2076-8.

77. Clark IA, Budd AC, Alleva LM, Cowden WB. Human malarial disease: a consequence of inflammatory cytokine release. Malar J. 2006;5:85.

78. Lyke KE, Burges R, Cissoko Y, Sangare L, Dao M, Diarra I, et al. Serum levels of the proinflammatory IL-8, IL-10, tumor necrosis factor alpha, and IL-12 ( p70 ) in Malian children with severe Plasmodium falciparum malaria and matched uncomplicated malaria or healthy controls. Infect Immun. 2004;72:5630-7.

79. Mbengue B, Niang B, Niang MS, Varela ML, Fall B, Fall MM, et al. Inflammatory cytokine and humoral responses to Plasmodium falciparum glycosylphosphatidylinositols correlates with malaria immunity and pathogenesis. Immunity Inflamm Dis. 2016;4:24-34.

Ready to submit your research? Choose BMC and benefit from:

- fast, convenient online submission

- thorough peer review by experienced researchers in your field

- rapid publication on acceptance

- support for research data, including large and complex data types

- gold Open Access which fosters wider collaboration and increased citations

- maximum visibility for your research: over $100 \mathrm{M}$ website views per year

At $\mathrm{BMC}$, research is always in progress.

Learn more biomedcentral.com/submissions 